\title{
Editor-in Chief Letter
}

It has been almost 16 months since I took over as Editor-in-Chief (EiC) of ACM TOS. Through the first issue of 2018, it seems like the right time to look back at some of the things that have happened and share some thoughts on where ACM TOS is headed.

Since taking the role of EiC, I have made major changes to the editorial board. Many have retired after many years of service, and I take this opportunity to thank them for their services. It takes a lot of effort and time to serve as an Associate Editor (AE), and I hope that everyone realizes the dedication that the AEs have for such voluntary service. If you know of anyone who has served in such positions, please take a moment to thank them for their services. With those leaving, many more have also joined in, and we now have a much larger group of AEs. In the same regard, I thank these AEs for taking up my offer to join and dedicating their time. They have already served nearly 1.5 years of their 2-year term. I am hoping that many of them will continue with a second 2-year term come summer of 2018.

As I took office, I have concentrated on three main efforts of improvement; turnaround time, increased submission, and exposure. I think we are moving positively on all three aspects. With the exception of a few submissions, reviews and decisions are being made within 3 months of submission. Looking back at the regular articles that I have received as EiC and that are currently accepted and/or published, our average time to acceptance has been roughly 6.5 months. This includes all reviews and revisions. I think this is a healthy number. The number of submissions has increased, and I hope this rate will remain stable with your interest and support. Finally, exposing and expanding the audience of TOS as the prime forum for storage publications is a matter that needs effort from all of us in this community. Our AEs are active experts in the storage community as well as reviewers and authors of articles submitted. They have joined as AEs because they consider TOS as a top forum, as should everyone in the community. In the same line, with cooperation from chairs of each conference, I have continued the tradition of FAST and MSST issues. Furthermore, as with this issue, I solicit special issue applications, so that TOS may cover topics not traditionally considered as mainstream storage. With the publication of this NVM special issue, I would like to announce that the area of "Emerging Memory Storage Technologies" will be explicitly included in our research scope. I hope to have TOS cover all areas related to nonvolatile memory.

Finally, I take this opportunity to thank all of you, readers, reviewers, authors, Associate Editors, the ACM staff, and my assistants Young Je and Eunjae, for your continued interest and support for ACM TOS. May the Year of the Dog bring you happiness and prosperity!

Sam H. Noh

Editor-in-Chief

ACM Transactions on Storage

Professor and Dean, School of Electrical \& Computer Eng. UNIST (Ulsan National Institute of Science \& Technology) Ulsan, KOREA

http://next.unist.ac.kr

2018 Copyright is held by the owner/author(s).

1553-3077/2018/02-ART1

https://doi.org/10.1145/3180478 